\title{
Effectiveness of lever sign test for diagnosing anterior cruciate ligament rupture
}

\author{
Naveed Ali Shair ${ }^{1}$, Umair Abubakar Siddiq², \\ Abdullah Tariq ${ }^{3}$, Muhammad Khalid ${ }^{4}$
}

\begin{abstract}
Objective: To evaluate the effectiveness of the Lever Sign test (LST) for diagnosing anterior cruciate ligament $(\mathrm{ACL})$ ruptures.

Methods: This prospective trial was conducted from January to December 2020. A total of 73 patients, aged 18 to 65 years, presenting with chief complaint as acute knee pain rated $<7 / 10$ on a verbal numerical rating scale, having a minimum 20 to $120^{\circ}$ range of motion and undergoing magnetic resonance imaging (MRI) were enrolled. Detailed history, physical examination and standard radiographic evaluation were done in all subjects. For the assessment of the integrity of the $\mathrm{ACL}$, the anterior drawer, Lachman, pivot-shift and LST were performed on each symptomatic knee by a senior orthopedic consultant with a minimum five years post-fellowship experience. Sensitivity, specificity, positive predictive value (PPV), negative predictive value (NPV) and accuracy of the LST were recorded with respect to standard reference MRI findings.

Results: Out of a total of 73 patients, there were $49(67.1 \%)$ males. Mean age was noted to be $34.5 \pm 8.1$ years. Area of residence was rural among $42(57.5 \%)$ patients. Mean time since injury was noted to be $11.2 \pm 4.6$ months. The MRI findings showed $A C L$ intact among $31(42.4 \%)$ patients while it showed ACL torn among $42(57.5 \%)$ patients. The LST showed positive findings for ACL rupture in $39(53.5 \%)$ patients while it was negative in remaining 34 (46.5\%). The sensitivity, specificity, PPV, NPV and accuracy of LST with respect to standard reference finding (MRI) was found to be $86 \%, 90 \%, 92 \%, 82 \%$ and $88 \%$ respectively.

Conclusion: The LST was found to have good specificity, sensitivity, PPV, NPV and accuracy to detect the status of the ACL. The LST is easy to perform can be used along with other standard assessment techniques to further increase the validation of the status of the $A C L$ diagnosis.
\end{abstract}

KEYWORDS: Anterior cruciate ligament, Lever sign test, Magnetic resonance imaging.

doi: https://doi.org/10.12669/pjms.38.4.4993

How to cite this:

Shair NA, Siddiq UA, Tariq A, Khalid M. Effectiveness of lever sign test for diagnosing anterior cruciate ligament rupture. Pak $J$ Med Sci. 2022;38(4):946-949. doi: https://doi.org/10.12669/pjms.38.4.4993

This is an Open Access article distributed under the terms of the Creative Commons Attribution License (http://creativecommons.org/licenses/by/3.0), which permits unrestricted use, distribution, and reproduction in any medium, provided the original work is properly cited.

1. Naveed Ali Shair, FCPS (Ortho)

2. Umair Abubakar Siddiq, FCPS (Ortho) Department of Orthopedic Surgery,

Central Park Medical College Lahore, Pakistan.

3. Abdullah Tariq, FCPS (Ortho)

Department of Orthopedic Surgery,

DHQ Hopsital, Nanakana Sahab, Lahore, Pakistan.

4. Muhammad Khalid, FCPS (Ortho)

1-4: Department of Orthopedic Surgery,

Lahore General Hospital, Lahore, Pakistan.

Correspondence:

Dr. Naveed Ali Shair

Department of Orthopedic Surgery,

Lahore General Hospital, Lahore, Pakistan.

E-mail: dr_malik912@yahoo.com

* Received for Publication:

* $1^{\text {st }}$ Revision Received:

* $2^{\text {nd }}$ Revision Received:

* Final Revision Accepted:
July 7, 2021

July 26, 2021

December 15, 2021

December 28, 2021

\section{INTRODUCTION}

The anterior cruciate ligament (ACL) is the most frequently involved knee injuries. ${ }^{1}$ ACL tears are calculated to be responsible for around $20 \%$ of all knee injuries while studies from USA estimated about 120,000 ACL injuries annually. 2,3

Arthroscopic visualization is known to be the "Gold Standard" used for diagnosing ACL rupture. ${ }^{4}$ Magnetic resonance imaging (MRI) is considered to be a valid yet non-invasive tool for the diagnosis of the ACL ruptures with specificity and sensitivity between $94-98 \% .^{5}$ The Lachman test, the anterior Drawer test and pivot shift test are the most frequently adopted physical examinations 
for diagnosing ACL ruptures. All these tests are known to produce good specificity and sensitivity yet these have their own limitations like the influence of the individual guarding because of pain linked with rapidly translating or twisting a potential injury whereas it is also known that partial tears are not easy to diagnose. ${ }^{6}$ Even these manual methods have some limitations, yet, these have some advantages over MRI as these are totally non-invasive and easily performed while these are also inexpensive contrary to MRI. ${ }^{7}$

The Lever Sign Test (LST) was introduced as a new physical test and has been in use since its introduction. ${ }^{7}$ Some researchers have shown LST to be better or equal to other manual tests while some others have shown it to be below par in comparison to other available manual options..$^{8,9}$ No data about the validity of LST exists in Pakistan so the present research was aimed at evaluating effectiveness of LST for diagnosing ACL ruptures.

\section{METHODS}

This prospective trial was conducted at "The Department of Orthopedic Surgery, Lahore General Hospital, Lahore", from January to December 2020. Approval from "Institutional Ethical Committee" was taken for this study (Ref\#603/20, dated: 02-112020). Written consent was sought from all study participants.

A total of 73 patients, aged 18 to 65 years, presenting with chief complaint as acute knee pain rated $<7 / 10$ on a verbal numerical rating scale, having a minimum 20 to $120^{\circ}$ range of motion and undergoing MRI were enrolled. All cases with suspected fractures as per "Ottawa Knee Rules", or having any previous knee joint arthroplasty, suspected posterior cruciate ligament involvement, past knee operations in the last six months or those who were having any major underlying non-mechanical pathological condition or systemic illnesses were not included.

Detailed history, physical examination and standard radiographic evaluation were done in all subjects. For the assessment of the integrity of the ACL, the anterior drawer, Lachman, pivot-shift and LSTs were performed on each symptomatic knee by a senior orthopedic consultant with a minimum five years post-fellowship experience. Orthopedic consultant performing the tests was blinded by the radiographic and MRI findings. The anterior drawer, Lachman and pivot-shift testes were done as described by Mulligan EP et $\mathrm{al}^{10}$ while LST was performed as detailed by Lelli A et al. ${ }^{8}$ All these four tests were done as dichotomous tests.
A special proforma was designed to record all relevant study data. For data analysis, SPSS version 26.0 was used. Gender and side involved were represented as frequency and percentages. Age (years), duration of injury (days), thigh circumference $(\mathrm{cm})$ and calf circumference $(\mathrm{cm})$ were represented as mean and standard deviation. Sensitivity, specificity, positive predictive value $(\mathrm{PPV})$, negative predictive value (NPV) and accuracy were recorded for all the 4 types of examination maneuvers for all study cases.

\section{RESULTS}

Out of a total of 73 patients, there were 49 $(67.1 \%)$ male. Mean age was noted to be $34.5 \pm 8.1$ years while $53(72.6 \%)$ patients were above 30 years of age. Area of residence was rural among $42(57.5 \%)$ patients. Mean time since injury was noted to be $11.2 \pm 4.6$ months. Most of the cases, $40(54.8 \%)$ had involvement of left knee. Characteristics of all cases involved in the present study are shown in Table-I.

The MRI findings showed ACL intact among 31 $(42.4 \%)$ patients while it showed ACL torn among $42(57.5 \%)$ patients. The LST showed positive findings for ACL rupture in $39(53.5 \%)$ patients while it was negative in remaining $34(46.5 \%)$. Sensitivity, specificity, PPV, NPV and Accuracy of LST with respect to standard reference finding (MRI) and those were found to be $86 \%, 90 \%, 92 \%$, $82 \%$ and $88 \%$ respectively. Table-II

Table-I: Characteristics of Study Participants ( $\mathrm{n}=73$ ).

\begin{tabular}{|c|c|c|}
\hline \multicolumn{2}{|c|}{ Characteristics } & $\begin{array}{c}\text { No. }(\%) / \\
\text { Mean } \pm S D\end{array}$ \\
\hline \multirow{2}{*}{ Gender } & Male & $49(67.1 \%)$ \\
\hline & Female & $24(32.9 \%)$ \\
\hline \multicolumn{2}{|l|}{ Age (years) } & $34.5 \pm 8.1$ \\
\hline \multirow{2}{*}{$\begin{array}{l}\text { Area of } \\
\text { Residence }\end{array}$} & Rural & $42(57.5 \%)$ \\
\hline & Urban & $31(42.5 \%)$ \\
\hline \multirow{3}{*}{$\begin{array}{l}\text { Time Since } \\
\text { Injury }\end{array}$} & Acute Phase (<3 weeks) & $16(21.9 \%)$ \\
\hline & Sub-acute Phase (3-11 weeks) & $28(38.4 \%)$ \\
\hline & Chronic Phase ( $\geq 12$ weeks) & $29(39.7 \%)$ \\
\hline \multirow{2}{*}{$\begin{array}{l}\text { Side In- } \\
\text { volved }\end{array}$} & Left & $40(54.8 \%)$ \\
\hline & Right & $33(45.2 \%)$ \\
\hline \multicolumn{2}{|c|}{ Thigh Circumference (cm) } & $45.8 \pm 6.1$ \\
\hline \multicolumn{2}{|c|}{ Calf Circumference $(\mathrm{cm})$} & $37.4 \pm 4.2$ \\
\hline
\end{tabular}


Table-II: Comparison to the Findings of Lever Sign

Test in Comparison to Reference Standard MRI Findings among Study Participants $(n=73)$.

\begin{tabular}{|c|c|c|}
\hline \multirow{2}{*}{ Lever Sign Test } & \multicolumn{2}{|c|}{ MRI Findings } \\
\hline & Positive & Negative \\
\hline Positive & $36(\mathrm{~A})$ & $3(\mathrm{C})$ \\
\hline Negative & $6(\mathrm{~B})$ & 28 (D) \\
\hline Sensitivity $=A /(A+B)$ & \multicolumn{2}{|c|}{$86 \%$} \\
\hline Specificity $=D /(C+D)$ & \multicolumn{2}{|c|}{$90 \%$} \\
\hline $\begin{array}{l}\text { Positive Predictive } \\
\text { Value }=A /(A+C)\end{array}$ & \multicolumn{2}{|c|}{$92 \%$} \\
\hline $\begin{array}{l}\text { Negative Predictive } \\
\text { Value }=D /(B+D)\end{array}$ & \multicolumn{2}{|c|}{$82 \%$} \\
\hline $\begin{array}{l}\text { Accuracy }=A+D / \\
(A+B+C+D)\end{array}$ & \multicolumn{2}{|c|}{$88 \%$} \\
\hline
\end{tabular}

Table-III is showing comparison of sensitivity, specificity, PPV, NPV and accuracy among Lever Sign and other tests performed among all study cases.

\section{DISCUSSION}

In the present study, MRI was considered to be the reference standard for comparing LST and various other kinds of manual maneuver/tests for their sensitivity, specificity, PPV, NPV and accuracy. In the past, the Lachman test has been found to be the most accurate and reliable manual test used for the diagnosis ACL ruptures while pivot-shift is considered to have the least amount of sensitivity among all the most commonly used manual tests for diagnosing ACL rupture. ${ }^{11,12}$

In this study, the LST was found to have sensitivity, specificity, PPV, NPV and accuracy as $86 \%, 90 \%, 92 \%, 82 \%$ and $88 \%$ respectively. There are very few studies conducted to test The LST in identifying ACL tears with respect to standard references like MRI or arthroscopy but some researchers in the past have presented the LST to have comparatively better sensitivities in comparison to its contemporary manual tests among acute and chronic ACL ruptures. However, we found the LST to have a better sensitivity than pivot-shift test ( $86 \%$ vs. $81 \%$ ) while sensitivity was comparable to anterior drawer and Lachman tests. Jarbo KA et al from USA evaluating accuracy of the LST for diagnosing ACL injuries employed different levels of testers like undergraduates, orthopedic residents and orthopedic fellows. ${ }^{13}$ The authors found overall sensitivity, specificity, PPV, NPV and accuracy of the LST to be $63 \%, 90 \%, 87 \%$, $71 \%$ and $77 \%$. The sensitivity, NPV and accuracy of the LST found by Jarbo KA et al is low that was found in the present study which could be due to the reasons that tester in the present study was an experienced orthopedic consultant (postfellowship experience of more than five years) so this could be the reason that higher rates of sensitivity and overall accuracy were found in the present study. Difference in ours and Jarbo KA et al. studies also demonstrate that there is a possible linkage between expertise of the examiner and outcome parameters of manual test performed among cases with possible ACL tears. ${ }^{13}$

Lelli A et al from Italy noted LST to diagnose $100 \%$ patients with complete ACL tears of both acute and chronic types while anterior drawer, the Lachman and pivot-shift tests were found to have sensitivities of $29 \%, 42 \%$ and $11 \%$ respectively. ${ }^{8}$ Thapa SS et al. and coworkers analyzed 80 cases with knee concerns following an injury and found sensitivities of the LST, anterior drawer, Lachman and pivotshift tests to be $86 \%, 80 \%, 91 \%$ and $51 \%$ which is close to what was found by us in the present study. ${ }^{9}$ Deveci et al analyzing 117 cases with confirmed diagnosis of ACL by arthroscopy compared preanesthesia and post-anesthesia findings of all four physical examinations. The authors noted the LST to have very good and comparable sensitivity, specificity, PPV, NPV and accuracy and concluded that the LST is an easy to apply clinical test which has higher sensitivity rates when compared to most applied the Lachman test. ${ }^{14}$

Table-III: Parameters of All Tests Performed versus MRI as Reference Standard ( $\mathrm{n}=73$ ).

\begin{tabular}{lccccc}
\hline Test & Sensitivity (\%) & Specificity $(\%)$ & PPV $(\%)$ & NPV (\%) & Accuracy (\%) \\
\hline Lever Sign & 86 & 90 & 92 & 82 & 88 \\
Anterior Drawer & 88 & 90 & 93 & 85 & 89 \\
Pivot Shift & 81 & 84 & 87 & 76 & 82 \\
Lachman & 93 & 93 & 95 & 91 & 93 \\
\hline
\end{tabular}


Although, the LST seems to be easy to apply test yielding good diagnostic validity but there seem to be few limitations as there are no validated biomechanical elucidation about the pathomechanics of the LST. ${ }^{15}$ Not much research has been done so far on the LST comparing this in different settings among different set patients contrary to the contemporary tests like anterior drawer, Lachman and pivot-shift tests which have large amount of studies available where these classical tests have been well studied and debated. We also don't know much about the validity of the LST with respect to differentiation in partial or complete ACL ruptures. In strength of the LST, it is easy to learn and perform. As there is not much rapid motion of the affected knee, additional pain is minimized during this test while some researchers have also reported that the test results for the LST are not affected even if the patient is awake or under anesthesia. $^{13}$

Limitations of the study:. Examiners were only blinded to the MRI diagnosis but not to the affected leg or side of the injury. We were unable to compare LST findings between the injured and the uninjured legs. We did not compare arthroscopic findings about ACL rupture with LST which would have further provided validity of this test. Further research should be done to further validate the findings of the LST in comparison to other existing tests. More research is also needed to find out evaluation of the LST among different levels of examiners and clinical settings.

\section{CONCLUSION}

The Lever Sign Test was found to have good specificity, sensitivity, PPV, NPV and accuracy to detect the status of the ACL. The Lever Sign test is easy to perform can be used along with other standard assessment techniques to further increase the validation of the status of the ACL diagnosis.

Grant Support \& Financial Disclosure: None. Conflict of Interest: None.

\section{REFERENCES}

1. Svantesson E, Senorski EH, Webster KE, Karlsson J, Diermeier T, Rothrauff BB, et al. Clinical outcomes after anterior cruciate ligament injury: panther symposium ACL injury clinical outcomes consensus group. Knee Surg Sports Traumatol Arthrosc. 2020;28(8):2415-2434. doi: 10.1007/ s00167-020-06061-x

2. Gawel J, Fibiger W, Starowicz A, Szwarczyk W. Early assessment of knee function and quality of life in patients after total knee replacement. Ortop Traumatol Rehabil 2010;12(1):329-337.
3. Pihlajamaki HK, Parviainen MC, Kautiainen H, Kiviranta I. Incidence and risk factors of exerciserelated knee disorders in young adult men. BMC Musculoskeletal Disord 2017;18(1):340-347.

4. Yaqoob J, Alam MS, Khalid N. Diagnostic accuracy of Magnetic Resonance Imaging in assessment of Meniscal and ACL tear: Correlation with arthroscopy. Pak J Med Sci. 2015;31(2):263-268. doi: 10.12669/ pjms.312.6499

5. Lefevre N, Naouri JF, Bohu Y, Klouche S, Herman S. Sensitivity and specificity of bell-hammer tear as an indirect sign of partial anterior cruciate ligament rupture on magnetic resonance imaging. Knee Surg Sports Traumatol Arthrosc. 2014;22(5):1112-1118. doi: 10.1007/s00167-013-2511-2

6. Saeed AA, Hassan MA, Zayed EM, Assy MA. The validity of Lever Sign test for the diagnosis of ACL injury. AlAzhar Med J. 2018;47(2):183-193. doi: 10.12816/0052247

7. Sarrafan N, Mehdinasab SA. Anterior cruciate ligament reconstruction using patellar tendon and quadriceps tendon: A comparative study. Pak J Med Sci. 2008;24(3):416-419.

8. Lelli A, Di Turi RP, Spenciner DB, Domini M. The "Lever Sign": A new clinical test for the diagnosis of anterior cruciate ligament rupture. Knee Surg Sports Traumatol Arthrosc. 2016;24(9):2794-2797. doi: 10.1007/ s00167-014-3490-7

9. Thapa SS, Lamichhane AP, Mahara DP. Accuracy of Lelli test for anterior cruciate ligament tear. J Inst Med. 2015;37(2):91-94.

10. Mulligan EP, Anderson A, Watson S, Dimeff RJ. The diagnostic accuracy of the lever sign for detecting anterior cruciate ligament injury. Int J Sports Phys Ther. 2017;12(7):1057-1067. doi: 10.26603/ijspt20171057

11. Torg JS, Conrad W, Kalen V. Clinical diagnosis of anterior cruciate ligament instability in the athlete. Am J Sports Med. 1976;4(2):84-93. doi: 10.1177/036354657600400206

12. Logan MC, Williams A, Lavelle J, Gedroyc W, Freeman M. Tibiofemoral kinematics following successful anterior cruciate ligament reconstruction using dynamic multiple resonance imaging. Am J Sports Med. 2004;32(4):984-992. doi: $10.1177 / 0363546503261702$

13. Jarbo KA, Hartigan DE, Scott KL, Patel KA, Chhabra A. Accuracy of the Lever Sign test in the diagnosis of anterior cruciate ligament injuries. Orthop J Sports Med. 2017;5(10):2325967117729809. doi: $10.1177 / 2325967117729809$

14. Deveci A, Cankaya D, Yilmaz S, Ozdemir G, Arslantas E, Bozkurt M. The arthroscopical \& radiological corelation of lever sign test for the diagnosis of anterior cruciate ligament rupture. Springerplus. 2015;4:830. doi: 10.1186/ s40064-015-1628-9

15. Lichtenberg $\mathrm{MC}$, Koster $\mathrm{CH}$, Teunissen LPJ, Oosterveld FG, Harmsen AM, Haverkamp D, et al. Does the Lever Sign test have added value for diagnosing Anterior Cruciate Ligament ruptures? Orthop J Sports Med. 2018;6(3):2325967118759631. doi: $10.1177 / 2325967118759631$

\section{Authors Contribution:}

NAS: Conceived, Responsible for data's integrity and authenticity, data collection.

UAS: Data Analysis, Drafting

AT: Literature Review, Discussion

MK: Formatting, Data Interpretation. 